\title{
Three-dimensional volumetric rendition of cannon ball pulmonary metastases by the use of 3D Slicer, an open source free software package
}

\author{
Swaroop Revannasiddaiah, ${ }^{1}$ Sridhar Papaiah Susheela, ${ }^{1}$ N Madhusudhan, ${ }^{1}$ \\ Govindarajan J Mallarajapatna²
}

${ }^{1}$ Department of Radiation Oncology, HealthCare GlobalBangalore Institute of Oncology, Bengaluru, Karnataka, India ${ }^{2}$ Department of Radiology \& Imaging, HealthCare GlobalBangalore Institute of Oncology, Bengaluru, Karnataka, India

\section{Correspondence to}

Dr Swaroop Revannasiddaiah, swarooptheone@gmail.com
To cite: Revannasiddaiah $\mathrm{S}$, Susheela SP,

Madhusudhan $\mathrm{N}$, et al. BMJ Case Rep Published online: [please include Day Month Year] doi:10.1136/bcr-2012008248

\section{DESCRIPTION}

A gentleman treated 6 years ago for colonic carcinoma (stage-IIA) had been on regular follow-up for a span of 4 years, when he was apparently diseasefree. After being lost to follow-up in the past 2 years, he was recently diagnosed with a pathological fracture of the seventh thoracic vertebra (figure 1) for which he underwent surgery

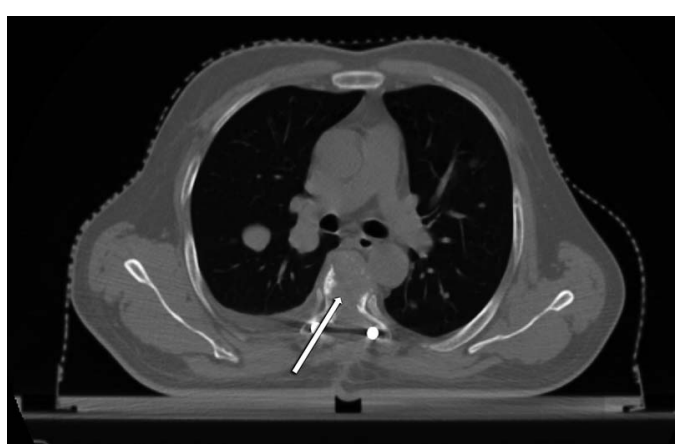

Figure 1 CT scan demonstrating the fractured seventh thoracic vertebral body (white arrow). (vertebral fixation and cord decompression) on an emergency basis.

Postoperatively, he underwent a CT simulation of the thorax with the purpose of planning radiotherapy (RT) to the involved vertebrae. The CT-scan demonstrated multiple bilateral pulmonary nodules (figure 2). After palliative RT to the involved vertebral column, in the interest of academics, we utilised the CT-scan data for volumetric reconstructions to attempt a better depiction of the wellknown phenomenon of 'cannon ball metastases'. ${ }^{12}$ This was achieved by the use of Slicer 4.2, an open source software package (distributed under a BSD-style open source license) intended for advanced visualisation and analysis of medical image datasets. ${ }^{3}$ This, to our knowledge, is possibly the first publication providing a three-dimensional depiction of 'cannon ball' pulmonary metastases (figure 3).

Slicer 4.2 is free to download and is available for use with the Linux, Mac and the Windows operating systems. ${ }^{4}$ While the package already contains numerous features, additional functionality can be via the in-built 'extension manager', which provides options to integrate various extra features. Though

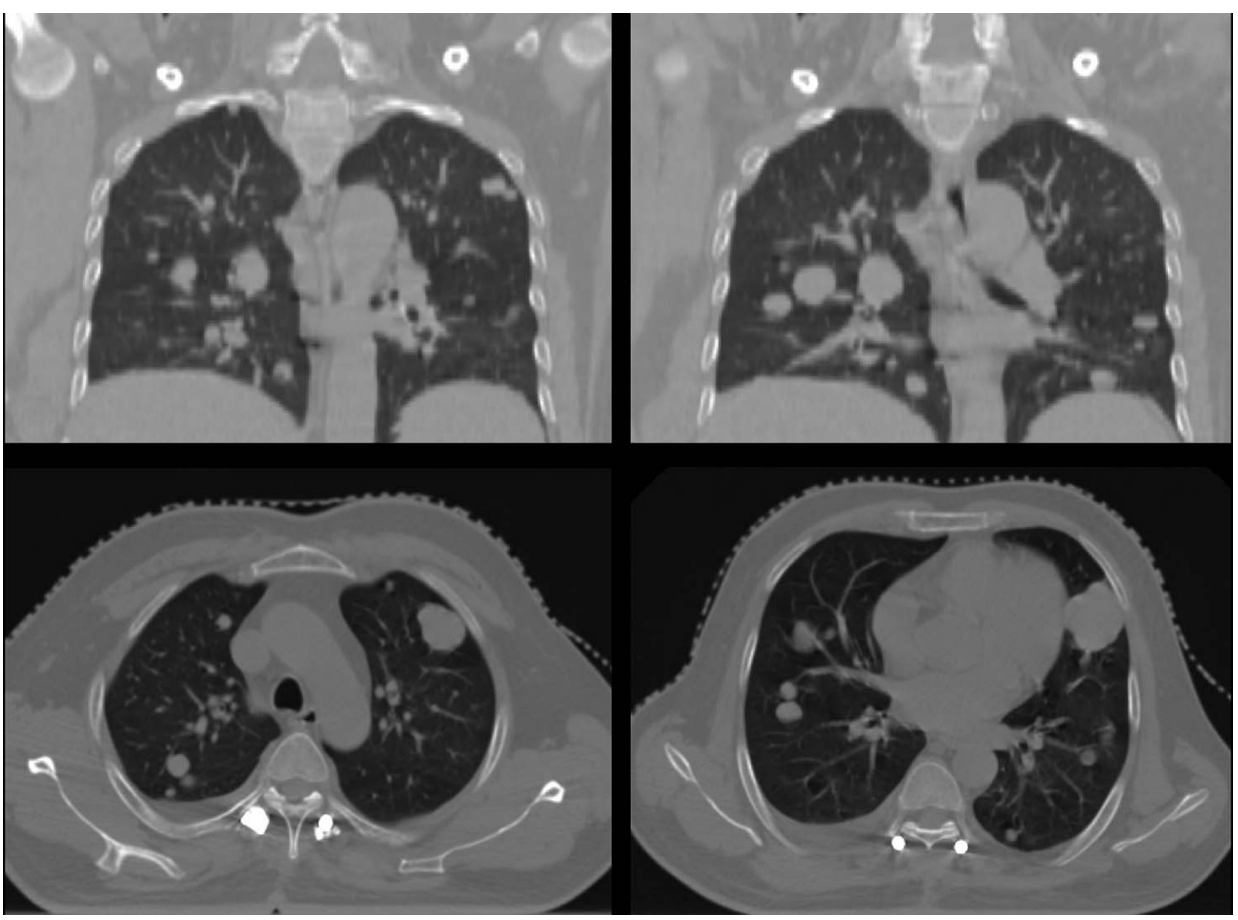

Figure 2 Multiple, bilateral pulmonary nodules ('cannon ball' metastases) on traditional axial and coronal slices. 


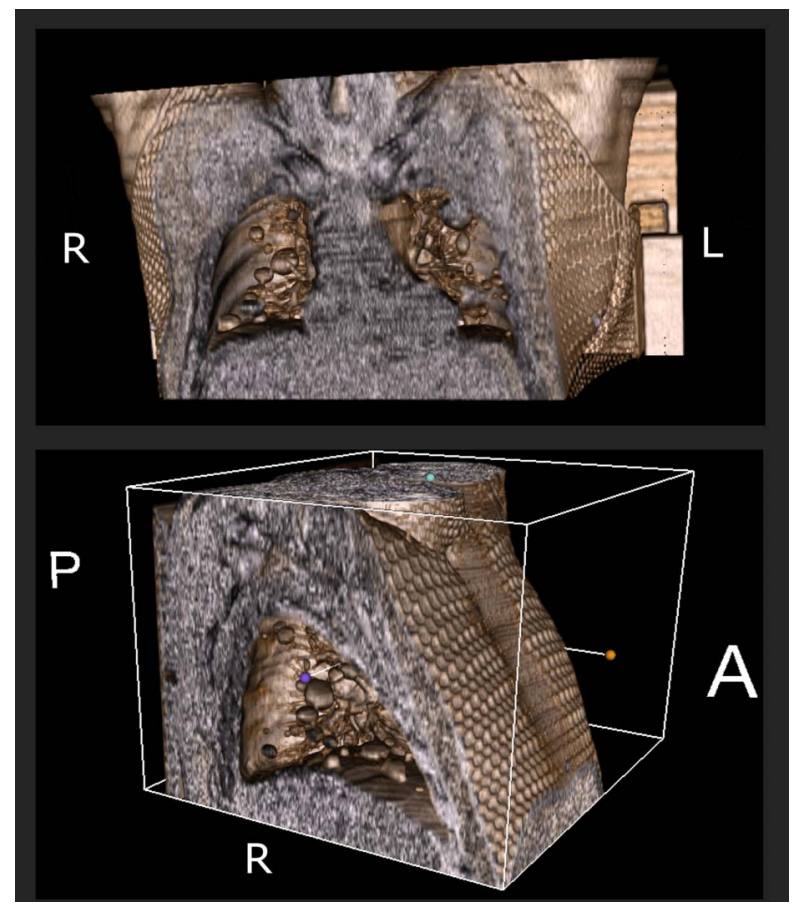

Competing interests None.

Patient consent Obtained.

Provenance and peer review Not commissioned; externally peer reviewed.

\section{REFERENCES}

1 Maizlin ZV, Kuruvilla M, Clement JJ, et al. Radiologic signs of weapons and munitions: how will noncombatants recognize them? AJR Am J Roentgenol 2010;195:W96-104.

2 Crow J, Slavin G, Kreel L. Pulmonary metastasis: a pathologic and radiologic study. Cancer 1981:47:2595-602.

3 Slicer.org. Copyright 2012 The Brigham and Women's Hospital and 3D Slicer contributors. Boston: BWH and 3D Slicer Contributors; (cited 17 Dec 2012).: //www. slicer.org/pages/License (accessed 10 Dec 2012).

4 Slicer.org. Copyright 2012 The Brigham and Women's Hospital and 3D Slicer contributors. Boston: BWH and 3D Slicer Contributors; (cited 17 December 2012).: //http://download.slicer.org (accessed 10 Dec 2012).

Figure 3 Three-dimensional rendition generated out of the thoracic CT-scan data, demonstrating 'cannon balls' within the lungs.

it is not currently approved for clinical use, it can, however, be used freely for academic research.

\section{Learning points}

- The importance of adherence to follow-up remains undiminished even after initial years of uneventful follow-up, regardless of the stage of cancer.

- Volumetric imaging data from sectional imaging can be digitally reconstructed to provide enhanced visualisation of normal and pathological anatomy.

- Slicer 4.2 can be downloaded freely from http://www.slicer. org/pages/License, and being a feature-rich open source alternative to expensive commercial software, it can handle complex functions such as tractography, multivolume processing, etc.

- Though not approved for clinical use, Slicer 4.2 can freely be utilised for research purposes.

Copyright 2013 BMJ Publishing Group. All rights reserved. For permission to reuse any of this content visit http://group.bmj.com/group/rights-licensing/permissions.

BMJ Case Report Fellows may re-use this article for personal use and teaching without any further permission.

Become a Fellow of BMJ Case Reports today and you can:

- Submit as many cases as you like

- Enjoy fast sympathetic peer review and rapid publication of accepted articles

- Access all the published articles

- Re-use any of the published material for personal use and teaching without further permission

For information on Institutional Fellowships contact consortiasales@bmjgroup.com

Visit casereports.bmj.com for more articles like this and to become a Fellow 